\title{
Comparison of Metacognitive Orientation between Thai Urban and Rural Physics Classrooms
}

\author{
Jirutthitikan Pimvichai \\ Chokchai Yuenyong* \\ Gegory P. Thomas \\ Sitthipon Art-in \\ Science Education Program, Faculty of Education, Khon Kaen University, Thailand \\ Email: ychok@kku.ac.th
}

\section{Doi:10.5901/mjss.2015.v6n3s1p193}

\section{Abstract}

The concept of metacognition which refers to the knowledge of an individual's control and awareness of their learning processes can be used to build Thai students' higher-thinking skills. This research aimed to describe the metacognitive orientation of the teaching and learning environment in Thai physics classrooms between urban and rural schools. It looks at situations that support the development of metacognition among the students in the classroom. The target group of the research is Grade 10 students in two urban and two rural schools in Khon Kaen Province. This research uses both quantitative and qualitative method. The MOLES-S instrument (Thomas, 2003) for evaluating students' metacognition is used to show how the learning environment in the physics classroom is able to support students' metacognition in the Thai context. This instrument is based on sociocultural view of learning which impact on the process of students' thinking, for instance, the interaction of teachers, students, and the classroom environment have important impact on students' thinking. The MOLES-S survey showed that the students in Thai Physics classrooms lack in metacognition. The implication of this is that students in both the urban and rural schools need to develop metacognition orientation in their physics classrooms to enhance their learning and achievement.

Keywords: Metacognition, Learning environments, Physics learning

\section{Introduction}

Thinking processes are considered as important to achieve high quality education that canused to develop students to grow up effectively in all aspects of intellect and morals, as well as being a good person in society. Current Thai research studies find that most students have ability in basic skills rather than higher-order thinking skills and the use of reason (ONEC 2002). Flavell (1979) uses the word "Metacognition" to explain that students learning processes will be aware of thinking processes in their own participative interaction between students and teachers, and in their physical, emotional, social and intellectual development. Metacognition is the process of thinking of thinking and describes that metacognitive is knowledge refers to an individual's personal or knowing not different cognitive. It's means thinking of knowledge or intelligence of any learning with understanding. Metacognition is the ability of knowledge that the students can think by their own the thinking process planning, control, self-monitoring, to make a system ensuring work to achieve its purpose effectively (Flavell, 1979). Thomas (2003) also mentioned that metacognition is the ability to thinking about their own thinking to the process of planning and control and monitoring their own the concept of system that can ensure the goals effectively. He also mentioned that metacognition include three components:

(1) Metacognition awareness that means of self-knowledge and understanding of the purpose of teaching as well as learning all aspects of each individual to learn in each activity. Awareness is the relationship between skills, strategies and results from the need to work to from experience brought about by explaining to others. Able be summarized meaning of what they learn or how to plan and reflect on their thoughts while using the existing experience or even in problem solving skill that will assist in the work plan of the individual. They know what works and what will include will get it to work efficiently and make the process as well as student (Baker and Brown, 1984). 
(2) Metacognitive Knowledge that is the knowledge an understanding of their thinking is not enough and there a limited scope of the person's awareness and control. Flavell (1979) stated that metacognitive knowledge means to be a part of all knowledge; the individuals have long term memory. Students will be able to learn from the prior experience as that existing; that if it happens to student is also required to find their next target by the factors that affect the thinking of their own.

(3) Metacognitive control that refers to the learners' ability to make adjustments in their own learning processes in response to their perception of feedback regarding their current status of learning. The concept of metacognitive control overlaps heavily with the preceding two terms; its focus is on the ability of the learners themselves to monitor their own learning (without external stimuli or persuasion) and to maintain the attitudes necessary to invoke and employ these strategies on their own. To learn most effectively, students should not only understand what strategies are available and the purposes these strategies will serve, but also become capable of adequately selecting, employing, monitoring, and evaluating their use of these strategies.(See Hallahan et al., 1979; Graham \& Harris, 1992; Reid \& Harris, 1989, 1993.).

However, despite evidence that metacognition is important for high-quality learning science classrooms (e.g. Tobin, 1993; Tobin \& Gallagher, 1987; Tobin \& Tippins, 1993), it hardly found some research to provide information of psychosocial attributes necessary for developing and enhancing students' metacognition. Therefore, means for informing educators, including teachers and researchers, of how they might enhance students' metacognition and how they might monitor changes in classrooms related to the effect of interventions and changes in pedagogy are necessary. In order to provide information of enhancing students' metacognition, Thomas (2003) developed an instrument called "Metacognitive Orientation Learning Environment Scale - Science (MOLES-S)" to measure the metacognitive orientation of science classroom learning environments. He defined a learning environment's metacognitive orientation as the extent to which that environment supports the development and enhancement of student participants' metacognition (Thomas, 2003).

This study aims to provide some information of how to enhance students' metacognition in physics learning environment. Physics is a scientific subject that is important to study subjects such natural phenomena in order to understand phenomena that occur and an introduction to the importance of higher education (Rosenthal, 1989; Aikenhead\& Ryan, 1992). For most students think physics is a difficult subject, difficult to grasp and understand that the course content on the calculation. Then, most students do not like it. Instruction physics classes in Thailand now usually focus on calculating and problem solving skills that focus on the process too much calculation. The main purpose is to test and study in higher education. Then, the nature of teaching and learning in this manner will result in achievement of students learning physics down were a lack of understanding of the conception in higher education. Therefore, it must be improvements in the instructional model for teaching and learning factors that have resulted in the improvement of learning achievement that includes significant Language ability and mathematical patterns of thinking and learning how to take the time to learn. From the above is that the model represents one of the factors affecting the development of academic achievement of students. Therefore, the process of thinking or metacognition is important for student to learn. Metacognition is a tool that supports students's learning in a community such as schools: for example, students learn physics using higher-order thinking processes. The development of metacognition in learning in the classroom and the ideas of situated cognition are the arguments that show the influence of culture on student's cognitive process (Yuenyong and Narjaikaew, 2009). The learning environment of the physics classroom Thai context that probably encourage the students have formed different their own cognitive knowledge. Therefore, this research study planed to investigate the metacognitive orientation in Thai physics classroom and compared the finding between the rural and urban physics school.

\subsection{Research Aims and Research Questions}

This research aims to find the metacognitive orientation of the learning environment in the Thai physics classroom at both of urban and rural school. The explicit of students' metacognition in the Physics Thai classroom will show rationale for the following research questions:

1. How much metacognitive orientation occurs in Thai Physics classroom?

2. What are the differences in metacognitive orientation demonstrated between rural and urban schools?

\section{Methodology}

The research was conducted using two case studies which compared physics classrooms in urban and rural schools. It looked at student learning where the main emphasis was studying the development of sets of metacognitive orientation that were supported in the learning environment of the physics classroom. 


\subsection{Target Group}

The target group of this research is 190 Grade 10 students who 98 students studying in 2 urban schools and 92 students studying in 2 rural schools in Khon Kaen Province, Thailand. These four classrooms were observed by a non-participant researcher over a period of six months. Furthermore semi-structured interviews were conducted one-to-one with twenty students (five from each school). The data for student's understanding of their metacognitve orientation were analyzed using key informants from each school.

\subsection{Data collection}

Data were collected by video and audio-recording in the classrooms. This research used mixed methods of quantitative and qualitative research. The MOLES-S instrument developed by Thomas (2003) was used to show how the learning environment in the physics classroom is able to support students' metacognition in the Thai context. It uses sub scales covering various dimensions of metacognitive activity as perceived by students in the physics classroom for evaluating students' metacognitive orientation. This instrument is based on sociocultural view of learning which impacts on the process of students' thinking, for instance, the interaction of teachers, students, and the classroom environment have important impact on students' thinking.

\subsection{The MOLES-S}

MOLES-S stands for Metacognition Orientation Learning Environment Scale-Science. This instrument was adopted from Thomas (2003) and translated into a Thai version to study the metacognitive orientation of the learning environment in Thai physics classrooms. The MOLES-S consist of 35 item questionnaire utilizing a 5 point Likert scale for each of 7 subscales containing five items each. A summary of the 7 sub-scales of the MOLES-S is provided in Table 1. Each sub-scale covers various dimension of the metacognitive activity as perceived by student in the physics classroom. All items development of previous learning environment instruments. Further, the instrument is premised on the previous that in addition to engaging students in activities such as, for students to be explicitly made aware of why and how such activities and their associated cognitive processes contribute to their learning so they can develop knowledge, control and awareness of such activities and processes. In other words, such activities, While valuable for learning science, and used in science classroom, may not necessarily by themselves lead to the development and enhancement of metacognition that is adaptive for students. Rather, they should form the basis of explication and discussion of the thinking process associated with them as a reasonable means to develop metacognition. The MOLES-S also incorporates dimensions such as student voice and distributed control, derived from critical theory and reflected in the Constructivist learning environment survey(Taylor, Fraser, \&White, 1994), and teacher encouragement and emotional support, which are not prominent in the metacognition literature but are justifiably important for the development and enhancement of student's metacognition (Thomas, 2003).

Table 1: Description of Scales and a Sample Item for Each Scale on the Initial Version of the MOLES-S (Thomas, 2003, p. 184)

\begin{tabular}{lll}
\hline Scale name & Description Sample item (Extent to which:) & Sample item (In this Physics classroom :) \\
$\begin{array}{l}\text { acognitive demands } \\
\begin{array}{l}\text { Teacher modeling and } \\
\text { explanation }\end{array}\end{array}$ & $\begin{array}{l}\text { Students are asked to be aware of how they learn and how they } \\
\text { can improve their they physics learning. }\end{array}$ & $\begin{array}{l}\text { Students are asked by their teacher to think about } \\
\text { how I learn physics. }\end{array}$ \\
\hline $\begin{array}{l}\text { Student-student discourse } \\
\text { them by the teacher. }\end{array}$ & Students discuss their science learning processes each other. & $\begin{array}{l}\text { Students discuss with each with other about } \\
\text { different ways of learning physics }\end{array}$ \\
\hline Student-teacher discourse & $\begin{array}{l}\text { Students discuss their science learning processes with their } \\
\text { teacher. }\end{array}$ & $\begin{array}{l}\text { Students discuss with their teacher about how } \\
\text { they can improve their learning of physics }\end{array}$ \\
\hline Student voice & $\begin{array}{l}\text { Students feel it is legitimate to question the teacher's } \\
\text { pedagogical plans and methods. }\end{array}$ & $\begin{array}{l}\text { It is OK for students to ask the teacher why they } \\
\text { have to do a certain activity. }\end{array}$ \\
\hline Distributed control & $\begin{array}{l}\text { Students collaborate with the teacher to plan their learning as as } \\
\text { they develop as autonomous learners }\end{array}$ & $\begin{array}{l}\text { Students help the teacher decide which activities } \\
\text { are best for them. }\end{array}$ \\
\hline Teacher encouragement \& support & $\begin{array}{l}\text { Students are encouraged by the teacher to improve their } \\
\text { Physics learning processes. }\end{array}$ & $\begin{array}{l}\text { The teacher supports students who try to improve } \\
\text { their Physics learning. }\end{array}$ \\
\hline Emotional support & $\begin{array}{l}\text { Students are cared for emotionally in relation to their science } \\
\text { learning. }\end{array}$ & \begin{tabular}{l} 
Students' ideas are respected. \\
\hline
\end{tabular}
\end{tabular}




\subsection{Data Analysis}

Students' rating on MOLES-S was computed for rating mean on each categories of the MOLES-S. The mean was interpreted to monitor the degree for each category of learning environment' s metacognitive orientation; $4.45-5.00=$ Almost Always, $3.45-4.44=$ often, $2.45-3.44=$ sometimes, $1.45-2.44=$ seldom, and less than $1.45=$ almost never; respectively. Students' behavior and ideas were also observed and interviewed to interpret what and how they perceived about physics learning environment's metacognitive orientation. Students' behavior and ideas, therefore, were categorized and interpreted to represent their monitoring on each aspect of metacognitive orientation.

\section{Results}

The MOLES-S is a questionnaire for looking at student understands of metacognition in Thai physics classrooms. After student answered the questionnaire, some of them were interviewed to probe further how and what they understand about metacognition. The 7 dimensions of metacognitive orientation of each student work were compared and contrasted by mean scale, SD, and P-value of each item of the MOLES-S. One dimension in MOLES-S about the teacher modeling and explanation for developing of metacognition in physics classroom was not included because this aspect will be dealt with in next study. Therefore classroom observations and the interviews were analysed under the remaining 7 dimensions of the MOLES-S scale. Thus the metacognitive orientation of Thai physics classroom in rural and urban schools will be discussed under the headings of metacognitive demands, student-student discussion, student-teacher discourse, student voice, distributed control, teacher encouragement and support, and emotional support.

\subsection{Metacognitive demands}

Metacognitive demands require teachers' providing learning environment in five issues. These included 1) students are asked to think about how they learn science, 2) students are asked by to explain how they solve science problems, 3) students are asked to think about their difficulties in learning science, 4) students are asked to think about how they could become better learners of science, and 5) students are asked to try new ways of learning science. It seems that urban school students' thinking in self-control had more development of metacognition proess than the rural school students. There is no significantly difference on five issues of metacognitive demands for urban school and rural school. However, urban school learning environment showed the lowest scale mean $(3.16,63.20 \%)$ on metacognitive demands in issues 2 . The rural school learning environment on metacognitve demands showed the lowest scale mean $(3.22,64.53 \%)$ in issue 5.

Table 1. Comparison of Urban school students ( $\mathrm{N}=98)$ and Rural school students ( $\mathrm{N}=92)$ on Metacognitive demand

\begin{tabular}{|c|c|c|c|c|c|c|c|}
\hline \multirow{2}{*}{ Metacognitive demands } & \multicolumn{2}{|c|}{ Scale mean } & \multicolumn{2}{|c|}{ SD } & \multirow{2}{*}{$d f$} & \multirow{2}{*}{$F$} & \multirow{2}{*}{$\begin{array}{c}\mathrm{p}- \\
\text { value }\end{array}$} \\
\hline & US & RS & US & RS & & & \\
\hline 1.Students are asked by the teacher to think about how they learn science & 3.42 & 3.55 & .952 & .634 & 1 & 1.337 & .249 \\
\hline 2. Students are asked by the teacher to explain how they solve science problems. & 3.16 & 3.30 & .995 & .659 & 1 & 1.128 & .290 \\
\hline 3. Students are asked by the teacher to think about their difficulties in learning science & 3.77 & 3.50 & 1.008 & .734 & 1 & 4.569 & .340 \\
\hline $\begin{array}{l}\text { 4. Students are asked by the teacher to think about how they could become better learners } \\
\text { of science. }\end{array}$ & 3.32 & 3.27 & 1.003 & .613 & 1 & .203 & .653 \\
\hline 5. Students are asked by the teacher to try new ways of learning science. & 3.26 & 3.22 & 1.082 & .895 & 1 & 1.568 & .212 \\
\hline
\end{tabular}

Urban school observation found that teacher asked students about their thoughts about their learning of physics in-depth interviews with students on the issue cognitive processes in science classroom. That teachers in a urban community an environment that is conducive to learning. With the application of knowledge from the instructor as a result, children can awareness them the knowledge that has been used in this study as students' reflection on the interview.

Interview:

Student: "There is some offline instructors to teach using problem on the board, then I think how offline."

Student: "Most of our teachers are to help solving problems on the board physics professor who has problems to Yes."

Rural school observation revealed that teachers usually taught in a manner to control the thought of it makes it impossible to apply the knowledge to teach the children the process of awareness self-control and learning. It is 
sometimes found in the learning process of students' thinking. These could be seen as following students' interviewing. Interview:

\begin{abstract}
Student: "Yes, most of it is to think of problems on the board set. Then a teacher took us back to figure out how to solve the house."

Student: "I think it is offline a review at the end of the lesson teachers will have to exercise their thoughts offline and try to understand the things that I learned how much "Sometimes they offer fun activities teachers or find a game during the afternoon because the school is a time to make sleepy."
\end{abstract}

This discussion in the classroom between teacher and students is that student will brainstorm ideas and share experiences in learning g physics. This will be more effective if teachers and students were asked to discuss the problems stared. This allows everyone to participate in learning to do in order to reflect the thinking of the students in learning physics. This issue will be presented to the relationship between teacher and students context in Thai society.

\title{
3.2 Student- student discourse
}

This is students -student discussions are the state of the teaching and learning in the classroom brainstorming with the students. Discuss knowledge and idea with each other. Discus and help each other to find ways to solve problems that occur during activities in the classroom in learning physics. This encourages a sense of enthusiasm to learn interested in what students are interested in this issue reflects the relationship between student and friends in the classroom. The rating of metacognitive orientation on students -student discussions comparing between Thai urban schools and rural schools showed in Table 2. It seems that rural schools had higher mean of rating scale than urban schools on all issues of student-student discussion. It showed that rating on issue 10 was lowest mean scale both in urban (2.76) and rural (3.15) schools. However, almost all issues were categorized in sometime level except issue 6 of rural schools. Even though all issues were rated in sometime level, we found some evidences of student-student discussion during classroom observation.

Urban schools observation keeping in mind that urban schools students will study the values of knowledge outside the classroom rather the urban community of competition, the students are learning values that will further their knowledge. Most students will talk in border to get a good score. This behavior (Charon, 1995) says that other in the group that think alike and in the process of interaction of a certain behavior will become extra vigorously again. The interaction of the group is long and apparent when the activity of cooperation definition and cause increase in to recognizable. That is what is acceptable behavior within the group that consciously or Sub-consciously result of the interaction arising from the cooperation of ideas that became the basis of the culture of work. This discussion allows students think about the self and awareness of knowledge that has been used to the knowledge learned in the classroom outside the classroom.

Interview:

Student: "Yes, they talk about how to do my physics problems but not often, because my friends all of them mutually exclusive classes. Each of them will have a way of thinking to solve problem that are different according to each of my students."

Students: "I will opinion that to help in physics problem, we will lead the way or formula to which the answer was correct answers on the board for the group."

Table 2. Comparison of Urban school students ( $\mathrm{N}=98)$ and Rural school students ( $\mathrm{N}=92)$ on Student-student discourse

\begin{tabular}{|c|c|c|c|c|c|c|c|}
\hline \multirow{2}{*}{ Student-student discourse } & \multicolumn{2}{|c|}{ Scale mean } & \multicolumn{2}{|c|}{ SD } & & \multirow{2}{*}{$F$} & \multirow{2}{*}{ p-value } \\
\hline & US & RS & US & RS & & & \\
\hline 6. Students discuss with each other about how they learn science. & 3.05 & 3.49 & 1.003 & .817 & 1 & 8.325 & $.000^{*}$ \\
\hline 7. Students discuss with each other about how they think when they learn science & 3.18 & 3.38 & .988 & .776 & 1 & 4.098 & .444 \\
\hline 8. Students discuss with each other about different ways of learning science. & 3.12 & 3.37 & .934 & .837 & 1 & 4.006 & .470 \\
\hline 9. Students discuss with each other about how well they are learning science. & 2.90 & 3.35 & 1.056 & .793 & 1 & 10.952 & $.001^{*}$ \\
\hline 10. Students discuss with each other about how they can improve their learning of scien & 2.76 & 3.15 & .950 & .730 & 1 & 10.365 & $.002^{*}$ \\
\hline
\end{tabular}

Students in rural schools in the discussion in the classroom the results show that the students will talk about how to learning physics because of the contexts of the within the classroom environment there is no competition. The children's lack of enthusiasm and try to understand the physics students talked very little but there are many students in urban 
community because of the teacher. To matched the actives in the classroom. The small number of students in the classroom contexts, thus enabling students to interact and exchange knowledge with their students are much more easily than in urban community where the number or students. It is the interaction between students and the students and the students follow situated in a classroom situated, which would have knowledge of the interpretation of experience and behavior. The students in schools (Spradley, 1980) the students will exchange ides through talking and there was a significant interaction (Charon, 1995)

Interview:

Student: "When I run a group we will help you think should be done to me the recipe is a good substitute. The study of the examples in books or on the board or from a friend that I will help teach you how to do that, how do I answer this? " Researcher: "The answer was exactly the answer to this? We know how to explain it."

Students: "My friend will explain the application of the formula, and then took his place. If we remember the formula we can calculate it out."

Students: "When I was a physics problem. I think the students in pairs to match it with friends. Time to do physics problem, so we have to do to get a straight answer on the board here"

\subsection{Student teacher discourse}

The discussion in the classroom between teachers and students is that student will brainstorm ideas and share experiences in learning Physics. This will be more effective if teachers do not teach in class after the lecture to allow students to share their knowledge. Teachers and students were asked to discuss the problems started. This allows everyone to participate in learning to do in order to reflect the thinking of the students in learning physics. This issue will be presented to the relationship between teachers and students in urban and rural schools in the context of the relationship between teachers and students in the context of Thai society. According to Table 3, it showed that all issues about student-teacher discourse were categorized in sometime level both in urban and rural schools.

Table 3. Comparison of Urban school students $(\mathrm{N}=98)$ and Rural school students $(\mathrm{N}=92)$ on Student-teacher discourse

\begin{tabular}{|c|c|c|c|c|c|c|c|}
\hline \multirow{2}{*}{ Student-teacher discourse } & \multicolumn{2}{|c|}{ Scale mean } & \multicolumn{2}{|c|}{ SD } & & \multirow{2}{*}{$F$} & \multirow{2}{*}{ p-value } \\
\hline & US & RS & US & RS & & & \\
\hline 11. Students discuss with the teacher about how they learn science. & 2.48 & 3.18 & .888 & .824 & 1 & 31.146 & $.000^{*}$ \\
\hline 12. Students discuss with the teacher about how they think when they learn science. & 2.48 & 3.25 & .933 & .837 & 1 & 36.744 & $.000^{*}$ \\
\hline 13. Students discuss with the teacher about different ways of learning science. & 2.53 & 3.28 & 976 & .764 & 1 & 35.686 & $.000^{*}$ \\
\hline 14. Students discuss with the teacher about how well they are learning science. & 2.58 & 3.19 & 1.025 & .829 & 1 & 20.468 & $.000^{*}$ \\
\hline 15. Students discuss with the teacher about how they can improve their learning $\mathrm{c}$ & 2.59 & 3.30 & 1.044 & .923 & 1 & 24.728 & $.000^{*}$ \\
\hline
\end{tabular}

Urban schools observation revealed what they concerned about student-teacher discourse. In-depth interviews, keeping in mind those teachers interact with students in the classroom and outside the classroom than most. Since Thai culture was implanted children the fear of adults. The culture teaches children to respect and obey adults rather than conflict; this affects the process of cognition. The children did not dare to comment or ask your teacher social context learning. Vygotsky explained in the theory that Students will understand the ideas, the experience gained by society and their culture. To convey the cultural characteristics of the culture, beliefs and values to children what makes them think that they should think it would be appropriate (Shaffer, 1999) and Lave \& Wenger (1991) discusses the implications of the relationship of learning and participation of the environment. The students live in the cities that have been influenced by the value of access to the so-called "special education".

Interview:

Student: "I have mostly will be asking how to do physics problems that are technical or new ways of looking at learning in the classroom. The periodic availability of teachers, but it is less time, because I do not have the time."

Researcher: "I ask students during class time if students do not understand what they learn."

Student: "No, I asked the teachers to teach because mostly additional special learned. I do not understand where it's going to ask you a tutorial on the same course."

Researcher: Why not ask in the classroom?

Student: "No, my friend is thoughtful studying. And special classes are friendly and there are learned for less than my classroom." 
Schools is countryside areas found that the environment is not conducive to the education of children are due to lack of funds or lack of support for teaching and learning in schools. Teachers have a role in the interaction with students than teachers in urban schools. The context of the classroom is conducive to interaction with the students in the exchange between teachers and students learn better. But they did not dare even to ask the teacher. As a result, students have a relatively slow process of self-cognition. The culture of rural society communities without competition or values to classes because, family income is not enough to promote the learning of students. As a result, children in urban and rural differences in child development, learning skills, are thinking the context of the environment. It probably there are different some socioculture context between urban and rural. Lave (1996) has divided the theories related to understanding the context of learning of students by the nature of the relationship between abuse and what is done in the context of the theory to be explained on the basis of the role of experience.

Interview:

Researcher: "When I taught in the classroom. Students talked with have teachers about the methods to study physics." Student: "Yes, I'm asking is that I do and I will study physics to understand physics. Techniques do not."

Researcher: "How do I answer?"

Student: "I always surf the formulas and practice problems physics, but it will not."

Student: "There I was curious how I learned to understand the physics and physical problems can be difficult."

\subsection{Student Voice}

The rights of students in the science classroom in Thailand Thai people have strong beliefs on how parents and students by providing students and the discipline to obey the teacher and students. They cooperatively organized rules of the classroom learning how to respect the right of the other. Their duties responsibly the teachers have a role in creating the atmosphere in the classroom as possible. The teacher must be provided for teaching and learned in a warm, sunny, friendly and teachers should encourage students to ask questions if in doubt or do not understand the lessons taught the activities in the classroom. This issue will be presented to the relationship between teachers and students in the classroom for teaching and learning the rights of students during lessons and activities in the classrooms of schools in the urban and its schools in the Thai context.

The researchers found that rural school students perceived that they were provided learning environment regarding aspect of student voice. Almost all issues of student voice were rated on category of often level; except the issue 17. However, urban school students perceived that classroom was provided as student voice in sometime level for all issues.

Urban school observation suggested us to know how to manage their own thinking. The students have the courage to ask the teacher. But sometimes the teacher is to give students the opportunity to comment. The activities in the classroom can help teachers and students in classrooms format sometimes. The Thai education system, teachers will design instruction in classrooms. This is in accordance with lesson plans for teachers and students into the study. In terms of teaching and learning in the process of meatcognition in that students can ask the teacher between the classroom activities found in the teaching and learning for some time. The reaching and learning in the classroom in the school by teachers and students can ask questions and express opinions on the design of learning activities from time to time in accordance with the Good, Miller, and Kessel (1995).

Interview:

Student: "Sometimes they offer fun activities teachers or find a game during the afternoon because the school is a time to make sleepy."

Table 4. Comparison of Urban school students ( $N=98)$ and Rural school students ( $N=92)$ Student voice

\begin{tabular}{|c|c|c|c|c|c|c|c|}
\hline \multirow[t]{2}{*}{ Student voice } & \multicolumn{2}{|c|}{$\begin{array}{l}\text { Scale } \\
\text { mean }\end{array}$} & \multicolumn{2}{|c|}{ SD } & \multirow[t]{2}{*}{$\mathrm{df}$} & \multirow[t]{2}{*}{$F$} & \multirow[t]{2}{*}{ p-value } \\
\hline & US & RS & US & RS & & & \\
\hline 16. It is OK for students to tell the teacher when they don't understand science. & 3.26 & 3.55 & 1.099 & .881 & 1 & 1.365 & .224 \\
\hline 17. It is OK for students to ask the teacher why they have to do a certain activity. & 3.43 & 3.33 & 1.085 & .883 & 1 & .250 & 617 \\
\hline $\begin{array}{l}\text { 18. It is OK for students to suggest alternative science learning activities to those proposed } \\
\text { by the teacher. }\end{array}$ & 2.87 & 3.57 & 1.115 & .919 & 1 & 9.995 & $.002^{*}$ \\
\hline 19. It is OK for students to speak out about activities that are confusing. & 3.30 & 3.52 & .989 & .854 & 1 & 4.367 & $.038^{*}$ \\
\hline 20. It is OK for students to speak out about anything that prevents them from learning. & 3.25 & 3.52 & .956 & .791 & 1 & 4.357 & $.038^{*}$ \\
\hline
\end{tabular}


Urban school observation suggested us to know how to manage their own thinking. The students have the courage to ask the teacher. But sometimes the teacher is to give students the opportunity to comment. The activities in the classroom can help teachers and students in classrooms format sometimes. The Thai education system, teachers will design instruction in classrooms. This is in accordance with lesson plans for teachers and students into the study. In terms of teaching and learning in the process of meatcognition in that students can ask the teacher between the classroom activities found in the teaching and learning for some time. The reaching and learning in the classroom in the school by teachers and students can ask questions and express opinions on the design of learning activities from time to time in accordance with the Good, Miller, and Kessel (1995).

\section{Interview:}

Student: "Sometimes they offer fun activities teachers or find a game during the afternoon because the school is a time to make sleepy."

This reflects that the child can think in the process of learning their own. Are aware of what they thought to want to enhance their own learning. There are also controls their own cognitive process along with the creativity of students in the class. The students were in schools in rural communities. The teacher can provide students the opportunity to comment. Resnick, Levine, \&Teasley (1991) discusses the mutual recognition in the society to offer a course that will help their students to think about their thinking processes. The opportunity to ask questions and activities for students to adopted knowledge to use in daily life. Lave \& Wenger (1991) discusses the significance of learning and participation of the environment. But, most often they do not want to idea about their own process because that is hard and long for them. Interview:
Student: "Yes, it is time to teach us. We wanted provide do was to take each problem together because some problems cannot do it myself."
Researcher: "The teacher asked the students while the students do not understand."
Student: "Most of my friends that I have asked. I do not understand, it will rely on the teacher to explain and do away with the fear in a room that is impediment friends."
Student: "My teachers and friends the opportunities to ask questions, but most are described along with the proposition that teachers instruct students to understand me and my friends together."

\subsection{Distributed control}

Distributed control study in the science classroom means that teachers provide students with idea decision. In the atmosphere in the classroom the students have the time to learn cache other as well as activities in the classroom. Kaser (2000) said the success and failure in education is an important factor conditions. Whether it's learning in science class interaction between teacher and student school students, or even be perceived as a discipline and an overview of teaching and learning in the classroom should be conducive to a variety of activities throughout the day. The classes should be taught to teachers according to student needs students' social and emotional. This issue will be presented to the relationship between teachers and students in the classroom for teaching and learning in the sharing of urban schools and schools in rural areas in Thai context. According to Table 5, interestingly, it indicated that both urban and rural school students perceived science classroom learning environment was provided regarding on distributed control in seldom level. Only issues 22 and 23 were rated as sometime level by rural school students.

Table 5. Comparison of Urban school students $(\mathrm{N}=98)$ and Rural school students $(\mathrm{N}=92)$ on Distributed control

\begin{tabular}{|c|c|c|c|c|c|c|c|}
\hline \multirow{2}{*}{ Distributed control } & \multicolumn{2}{|c|}{ Scale mean } & \multicolumn{2}{|c|}{ SD } & \multirow[b]{2}{*}{$d t$} & \multirow{2}{*}{$F$} & \multirow{2}{*}{$p$-value } \\
\hline & US & RS & US & RS & & & \\
\hline 21. Students help the teacher plan what needs to be learned. & 1.28 & 1.32 & .459 & .467 & 1 & .082 & .774 \\
\hline 22. Students help the teacher decide which activities they do. & 2.20 & 2.88 & .824 & .907 & 1 & 29.917 & $.000^{*}$ \\
\hline 23. Students help the teacher to decide which activities are best for them. & 2.25 & 2.83 & 1.058 & .913 & 1 & 16.988 & $.000^{*}$ \\
\hline 24. Students help the teacher decide how much time they spend on activities. & 1.32 & 1.33 & .467 & .471 & 1 & .021 & .886 \\
\hline 25. Students help the teacher decide when it is time to begin a new topic. & 1.12 & 1.07 & .329 & .267 & 1 & 1.128 & .290 \\
\hline
\end{tabular}

The development of metacognition in the orientation that is one of the students, help teachers plan for learning science in the school has an average rating greater than in country areas. Make known the context of the current conditions of teaching in schools in both urban and rural were similar in terms of controlling the process of learning in the classroom. 
To be determined by teachers and educational activities designed to provide students more than the scheduled or planned in the curriculum. The urban schools have less than rural the work can be understood by considering the social context in which they are embedded (Wertsch and Toma, 1995), as they learn about the development of lesson plans and teaching focuses on the tools of culture for the link between the action. The school has expertise in teaching than the students. We can design a course of instruction is more effective than defined by the attendees themselves. This will result in the development process knowing idea their children better and to control children's behavior in class and develop their own ideas to be more orderly. From the MOLES-S, and in depth interviews with students, Make known that students will have the satisfaction of learning from the teacher, then because view as the Curriculum of teachers.

Interview:

Student: "I do not help Curriculum because teachers are prepared to teach by teaching."

Student: "I do not have to format the style of teaching because the teachers are prepared to teach."

\subsection{Teacher encouragement and support}

The process of promoting science in the classroom is to learn from data, information and experiences. Those support the student self-study learning knowledge and self-learning activities extensively and continuously. To enhance the students learning process and is learning to enhance the learning environment in schools. Focus on student is important Starting from the classroom and outside. The classroom in the school community, social and cultural program participants live. This issue will be presented to the relationship between teachers and students in the environment and teaching within the classroom. Teachers are encouraged to help support students in the higher-order thinking can improve their own learning they figure out new ways of learning in physics. According to Table 6, interestingly, it showed that urban school students perceived science metacognitive orientation learning environment was provided regarding on teacher encourage and support in often level for all issues. Unlike rural school students rated issues 27 and 28 on often level and issues 26, 29, and 30 on sometime level.

Table 6. Comparison of Urban school students $(\mathrm{N}=98)$ and Rural school students $(\mathrm{N}=92)$ on Teacher encouragement and support

\begin{tabular}{|c|c|c|c|c|c|c|c|}
\hline \multirow[t]{2}{*}{ Teacher encouragement and support } & \multicolumn{2}{|c|}{$\begin{array}{l}\text { Scale } \\
\text { mean }\end{array}$} & \multicolumn{2}{|c|}{ SD } & \multirow[t]{2}{*}{ df } & \multirow[t]{2}{*}{$\mathrm{F}$} & \multirow{2}{*}{$\begin{array}{c}\mathrm{p}- \\
\text { value }\end{array}$} \\
\hline & US & RS & US & RS & & & \\
\hline 26. The teacher encourages students to try to improve how they learn science & 3.45 & 3.43 & 1.141 & .829 & 1 & 0.28 & .867 \\
\hline 27. The teacher encourages students to try different ways to learn science & 3.46 & 3.56 & 1.027 & .774 & 1 & .647 & .422 \\
\hline 28. The teacher supports students who try to improve their science learning & 3.65 & 3.56 & 1.064 & .855 & 1 & .000 & .999 \\
\hline 29. The teacher supports students who try new ways of learning science & 3.58 & 3.40 & 1.044 & .974 & 1 & 1.485 & .224 \\
\hline 30. The teacher encourages students to talk with each other about how they learn science & 3.68 & 3.40 & 1.071 & .827 & 1 & 3.766 & .054 \\
\hline
\end{tabular}

For urban school students, this will allow the children to recommend what the teacher to improve their own learning process. Vygotsky believed that human beings have the intellectual development of the Zone of Proximal Development beyond this zone, if anyone can afford to learn and to educate themselves on their own without assistance. Those who are under this zone are those who cannot learn or solve problems on their own. Therefore to have the assistance is called Scaffolding in physics even to make the classroom activities. Teachers will encourage students to practice thinking and solve problems. Of in-depth interviews, we know the difference between students in urban and rural areas have different modes of learning to students from the MOLES-S in teacher support to improve student physics learning. Interview:

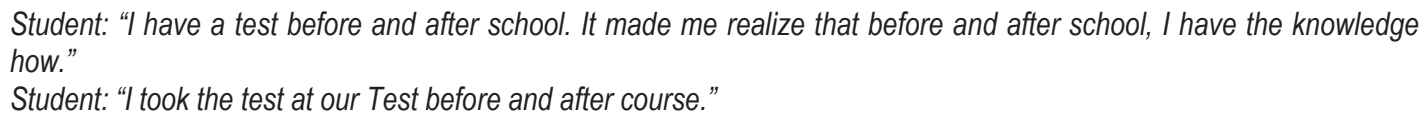

Rural Schools find it the process of promoting science in the classroom that sometimes. The Curriculum of teachers can affect the support that students are aware of their own thought process is rather small. Because, they prefer to give teachers a problem and solve problems along with the process of learn idea of them more. The students will need 
to train or practice with them. The teacher was trying to enter the thought process to students. Lave (1993) have divided the analysis of the theory in relation to understanding the context of a development. Theory that emphasizes action and discusses the nature of the relationship between abuse and what is done in context. The theory is based on the events described. When it comes to the role of work experience will be reminded of Dewey (Ansbacher, 1998; Cohen, 1998; Fenstermacher \& Sager, 1998).

Interview:

Student: "The teacher tries to bring physics to the problems we are thinking. Practice, because I know that we still do not understand. The teacher will give us problems we do a lot to understand about how to do it."

Student: "The teacher, we know that the formula is not The teacher will try to give us a formula to surf or go surfing on the subject at all times."

\subsection{Emotional support}

Emotional support within the science classroom is to promote behavioral change of students who have relationships with teachers in the areas of attitudes, beliefs, and attitudes, beliefs between teachers and students in the physics classroom. The importance and impact of positive and negative long-term develop in students learning. The classroom environment is a crucial part of the emotional support of students. The physical condition affects to the teacher and student's behavior. The class structure has great potential to improve both learning and behavior of students. The teacher appreciates the students' behavior and learning. The physical environment in the classroom is one way to make curriculum more effective, because the behavior is reduced and a much improved learning environment. This issue will be presented to the relationship between teachers and students to support and promote or encourage students in the classroom. As well as atmospheric conditions, the class course provide have warm, do not tension and to provide equality. Students will do not a bad attitude towards teachers in the physics curriculum in the context.

Table 7. Comparison of Urban school students ( $N=98)$ and Rural school students ( $N=92)$ on Emotion support

\begin{tabular}{|l|c|c|c|c|c|c|c|}
\hline \multirow{2}{*}{ Emotional support } & \multicolumn{2}{|c|}{ Scale mean } & \multicolumn{2}{|c|}{ SD } & \multirow{2}{*}{ df } & \multirow{2}{*}{$\mathrm{F}$-value } \\
\cline { 2 - 6 } & US & RS & US & RS & & & \\
\hline 31. Students are treated fairly. & 4.04 & 3.87 & 80.80 & 77.40 & 1 & 2.192 & .140 \\
\hline 32. Student' efforts are valued. & 3.63 & 3.69 & .935 & .861 & 1 & .233 & .630 \\
\hline 33. Student' ideas are respected. & 3.63 & 3.26 & .946 & .813 & 1 & 7.906 & $.005^{\star}$ \\
\hline 34. Student' individual differences are respected. & 3.89 & 3.77 & .891 & .875 & 1 & .810 & .369 \\
\hline 35. Student and the teacher trust each other. & 3.65 & 3.71 & 1.016 & .953 & 1 & .202 & .654 \\
\hline
\end{tabular}

According to Table 7, interestingly, it showed that almost all of metacognitive orientation on emotional support had mean rating scale in category of often level for both urban and rural school students. Only issue 33 was rated on sometime level by rural school students.

Students' interview reflected teacher's role in affected the thinking process of students. The promote students to practice the skills and knowledge to develop their own thinking processes. The program automatically awareness the own self and the ability to understand and control. To handle own self with the knowledge that has happened to them. The critical thinking skills not only in school but also, as well as lifelong learning as well. Metacognition refers to knowledge about the way the brain processes and brain processes (Eggen \& Kauchak, 1999). Metacognition is a form of selforganizing, directing, acting, and the process of moving data from one point to another. The teacher recognizes the equality of gifted children and babies. The knowledge level of students who have made sense to me and obey the teacher, the students go through the process of metacognition in the students them self.

Interview:

Student: "I've been unfair; because teachers always give the same picture is not goof students or good students.

Teachers would be interested as well."

Student: "I accept because they all have different character, and everyone has the ability to do the same."

Student: "Teachers a confident they are taking, and paraphrasing what is a good model for us."

The finding shown that student in the urban is eager to develop their thinking about all the time. The teacher is there to support and stimulate students' learning process in physics is quite a lot. The urban has quite a lot of competition 
in education, together with equipment and teaching personnel and experts. Students in rural areas, there is no enthusiasm and no interest in the development of their own. Teachers can only do we support and promote students to apply and implement in their own cognition. Because the context of the community upon graduation to the students not to take the knowledge of physics to study at university level, making them lack the skills learned in the process of thinking. The development of teachers, students and teachers are encouraged to support and enhance learning in physics are very few. The students just expect a level of education, the government has given only for go out and find a job in the urban. MOLES-S, 7 the topic in terms of teaching and learning conditions in the context of Thai society. Of the interview researchers found that urban school or rural school. The process made me think of would rather have a few because of the context of teaching and learning environment for teachers and cultural context. The values that affect the process of cognition of learner whether you are awareness even application about self-control process. This is especially important that we should turn their attention to developing students' thinking processes. The learning to be more efficient from a develop environment. In the classroom in the form of teaching to the modern form children about their thinking processes can that be in any social context, whether urban and rural areas. Thai students to study physics at present.

\subsection{Overview of comparisons of the MOLES-S Thailand urban schools and rural schools}

The Table 8 revealed the overview of comparisons of the MOLES-S to measure the learning process of students affect the teaching and learning in physics that affect the process of cognition of the urban school and rural school that have in the Thai context from the table II and graph shows that the discussion in science classrooms in urban schools with an average is $3.00(60.00 \%)$ and rural school with an average is $3.05(61.00 \%)$. The discussion in the classroom between teacher and student in urban schools with an average is 2.53 (50.60\%) and rural school with an average is 2.94 (58.80\%) (The differences were statistically significant at $\mathrm{P}<0.05$ ).

Table 8: The overview of comparisons of the MOLES-S Thailand urban schools and rural schools

\begin{tabular}{|c|c|c|c|c|c|c|}
\hline \multirow{3}{*}{ Scale } & \multirow{2}{*}{\multicolumn{2}{|c|}{$\begin{array}{c}\text { Urban school } \\
\mathrm{N}=98\end{array}$}} & \multirow{2}{*}{\multicolumn{2}{|c|}{$\begin{array}{c}\text { Rural School } \\
\mathrm{N}=92\end{array}$}} & \multirow{3}{*}{$t$} & \multirow{3}{*}{ sig } \\
\hline & & & & & & \\
\hline & Rating Mean & SD & Rating Mean & SD & & \\
\hline Metacognitive demands & $\begin{array}{l}3.38(67.60) \\
\text { Sometimes }\end{array}$ & 1.008 & $\begin{array}{l}3.41(58.2) \\
\text { Sometimes }\end{array}$ & 0.707 & -0.1762 & $0.143^{\mathrm{ns}}$ \\
\hline Student-student discourse & $\begin{array}{l}3.00(60.00) \\
\text { Sometimes }\end{array}$ & 0.986 & $\begin{array}{l}3.05(61.00) \\
\text { Sometimes }\end{array}$ & 0.790 & -2.6878 & $0.000^{*}$ \\
\hline Student-teacher discourse & $\begin{array}{l}2.53(50.60) \\
\text { Sometimes }\end{array}$ & 0.973 & $\begin{array}{c}2.94(58.80) \\
\text { Sometimes }\end{array}$ & 0.835 & -5.4228 & $0.000^{*}$ \\
\hline Student voice & $\begin{array}{l}3.49(69.80) \\
\text { Sometimes }\end{array}$ & 1.048 & $\begin{array}{l}3.47(69.40) \\
\text { Sometimes }\end{array}$ & 0.865 & -1.8012 & $0.093^{n s}$ \\
\hline Distributed control & $\begin{array}{c}1.64(32.80) \\
\text { seldom }\end{array}$ & 0.627 & $\begin{array}{c}1.88(37.60) \\
\text { seldom }\end{array}$ & 0.605 & -1.792 & $0.224^{\mathrm{ns}}$ \\
\hline Teacher encouragement and support & $\begin{array}{c}3.56(71.20) \\
\text { Often }\end{array}$ & 1.069 & $\begin{array}{l}.49(69.80) \\
\text { Sometime }\end{array}$ & 0.851 & 0.6324 & $0.513 \mathrm{~ns}$ \\
\hline Emotional support & $\begin{array}{c}3.77(75.40) \\
\text { Sometime }\end{array}$ & 0.865 & $\begin{array}{c}3.66(73.20) \\
\text { Sometime }\end{array}$ & 0.748 & 0.8524 & $0.179 n s$ \\
\hline
\end{tabular}

The urban schools promote students to think about how self-study solve problems on their own and try to motivate students to learn how to learn in their physics classes with new methods. Demonstrate a knowledge society where knowledge and ideas for people. Lead to a broader understanding of a group of people (Dixon-Kraussm, 1996). Vygotsky says that social and cultural factors are important (Confrey, 1995) with a view to social and cultural. The students should be aware of the relationship between makings their own culture and context in their live (Wertsch, Del Rio and Alvarez, 1995). Rogoff (1995) says that there should be a component in the development of learning into three areas: (1) training (2) participate in the recommendation, and (3) the appropriation. The urban school show more process of enhancing cognition in the classroom than the students in rural areas. The table also shows the differences the other two. The discussion in the classroom between teacher and student control classroom, which can be seen that the rural school will have an average percent more than in the urban school. As a condition of class, rural, the context of teaching the students more than students in rural schools and teachers. The opportunity to talk with students and wait's time for events to learn better than urban schools. The curriculum is based on a lesson plan for teachers to keep up with the time 
spent teaching. The theory has emphasized the development of contextual relationship of context with the recognition and learning, rather than looking at the role of academics in the context of Rogoff \& Lave (1984). That highlights the perception of everyday life, Resnick, Levine, \&Teasley (1991). The perception that social sharing Brow, Collins, \& Duguid (1989) discussed the training and work Lave \& Wenger (1991) said that the significant relationship between learning and participate of the environment. Reflect the dominant cultural context that encourages students to the process of metacognition in an existing minimum. By comparison, it is found that all students with the knowledge that are very few of the classes for metacognition in Thai context.

\section{Conclusion and Discussion}

These results find that when testing each topic schools that are teaching and learning in physics between urban and rural areas in the context of teaching and learning. Encouraged students to think about own self or called "Metacognition". The findings shown that teaching and learning in urban school stipulated in real situations. The classroom is a form of teaching that promotes the process of cognition of the students in the class (mean average, 3.05, 61\%) and schools located in rural communities to manage teaching and learning in real situations. The classroom has a teaching style that promotes the learning of students in a class (mean average, 3.08, 61.10\%). When the researcher looked at metacognition in Thai physics classroom, there are students have rather than metacognitive skills then students need to develop thinking skills, provide self-monitoring, provide self-confidence, improve care, attention ,motivation ,attitude, control by asking question to own self and learning process. The metacognition orientation this instrument is based on sociocultural view of learning which impact on the process of students' thinking, for instance, the interaction of teachers, students, and the classroom environment have important impact on students' thinking. The MOLES-S survey showed that the students in Thai Physics classrooms lack in metacognition. The implication of this finding is that students in both the urban and rural schools need to develop metacognition in their physics classrooms for enhanced their learning and achievement. Therefore, the metacognitive active learning through new teaching approach is included in physics lessons as in all learning environment. The research findings suggest the stage for the next research study which should look at strategies to develop and enhance argumentation and metacognitive orientation in both rural and urban Thai Physics classroom.

\section{Acknowledgement}

This work was supported by the Higher Education Research Promotion and National Research University Project of Thailand, Office of the Higher Education Commission, through the Cluster of Research to Enhance the Quality of Basic Education

\section{References}

Aikenhead, G.S., \& Ryan, A.G. (1992).The development of a new instrument: "Views on science-technology-society" (VOSTS). Science Education, 76(5), 477-491.

Ansbacher, T. 1998. John Dewey's Experience and Education: Lessons for Museums. Curator: The Museum Journal 41 (1): $36-49$.

Baker, L.y Brown A.L, (1984). Metacognitive skill and reading. En Pearson, P.D. Handbook of reading research (Manual de inverstigaion de la lecture (PP.353-394). EE.UU.:Longman

Brown, J. S., Collins, A., \&Duguid, P. (1989).Situated cognition and the culture of learning. Educational Researcher, 18, 32-42

Charon, Joel M. (1995). Symbolic Interactionism. An Introduction, an Interpretation, an Integration.Prentice Hall. Englewood Cliffs, New Jersey. Chevreau, Guy

Cohen, A. D. (1998). Strategies in learning and using a second language. Harlow, Essex: Longman.

Collins, A., Brown, J. S., \& Newman, S. E. (1987).Cognitive apprenticeship: Teaching the craft of reading, writing and mathematics (Technical Report No. 403). BBN Laboratories, Cambridge, MA. Centre for the Study of Reading, University of Illinois. January, 1987

Confrey, J. (1995). How Compatible are Radical Constructivism, Sociocultural Approaches, and Social Constructivism? In Steffe, L.P. and Gale, J. (Eds.). Constructivism in Education. New Jersey, USA: Lawrence Erlbaum Associates, Inc., 185 - 226.

Dixon-Kraussm, L. (1996). Vygotsky in the Classroom: Mediated Literacy Instruction and Assessment. New York, USA: Longman.

Eggen, P., \& Kauchak, D. (1999). Educational psychology: Windows on classrooms. (4th ed.). Upper Saddle River, NJ: Prentice Hall.

Flavell, J. H. (1979). Metacognition and cognitive monitoring: A new area of cognitive-developmental inquiry. American Psychologist, 34, $906-911$.

Fenstermacher, G. D. (2001). On the concept of manner and its visibility in teaching practice. Journal of Curriculum Studies, 33 (6), 639 653. 
Thomas, G. (2003). Conceptualization, development and validation of an instrument for Investigating the metacognitive orientations of science classroom learning environments: The Metacognitive Orientation Learning Environment Scale-Science (MOLESS).Learning Environment Research, 6, 175-197.

Graham, S., Harris, K.R., \& Reid, R. (1992).Developing self-regulated learners. Focus on Exceptional Children, 24 (6), 1-16.

Good, J. J., Miller, P. J., \&Kessel, F. (1995). Cultural practices as contexts for development. San Francisco :Jossey-Bass Publishers.

Hallahan, D. P., Lloyd, J. W., Kosiewicz, M. M., Kauffman,J. M., \& Graves, A. W. (1979). Self-monitoring of attention as a treatment for a learning disabled boy's off task behavior. Learning Disability Quarterly, 2(2): 24-32.

Lave, J. (1996). Teaching as learning, in practice. Mind, Culture \& Activity, 3(3): 149-164

Lave, J.; Wenger, E. (1991). Situated Learning: Legitimate Peripheral Participation. Cambridge: Cambridge University Press. ISBN 0521423740.; first published in 1990 as Institute for Research on Learning report 90-0013

Office of the National Education Commission (ONEC). (2002). Learning Reform: A Learner-Centred Approach. Bangkok, Thailand: Wattana Panit Printing \& Publishing Company Limited.

Resnick, L., Levine, J., \&Teasley, S. (Eds.). (1991). Perspectives on socially shared cognition. Washington, DC: American Psychological Association

Rogoff, B. (1995). Observing sociocultural activity on three planes: participatory appropriation, guided participation, and apprenticeship. In Wertsch, J.V.; Del Rio, P.D.; and Alvarez, A. (Eds.). Sociocultural Studies of Mind. New York, USA: Cambridge University Press. $139-164$.

Rogoff, B., \& Lave, J. (Eds.). (1984). Everyday cognition: Its development in social context. Cambridge, MA: Harvard University Press.

Rosenthal, R. D. (1989). Two Approaches to Science-technology-Society (S-T-S) Education. Science Education. $73(5): 581$ - 589.

Reid, R., \& Harris, K. R. (1993).Self-monitoring of attention versus self-monitoring performance: Effects on attention and academic performance. Exceptional Children, 60, 29-40.

Shaffer, D. (1999). Developmental psychology: Childhood \& adolescence. (5th Edition). Toronto, Brooks/Cole Publishing.

Spradley, James. 1980. Participant Observation. United States: Holt Rinehart and Winston Taylor, P.C., Fraser, B.J. \& White, L.R. (1994, April). The revised CLES: A questionnaire for educators interested in the constructivist reform of school science and mathematics. Paper presented at the annual meeting of the American Educational Research Association, Atlanta, GA.

Wertsch, J.V. (1995). The needs for action in sociocultural research. In Wertsch, J.V.; Del Rio, P.D.; and Alvarez, A. (Eds.). Sociocultural Studies of Mind. New York, USA: Cambridge University Press. 56 - 74.

Wertsch, J.V. and Toma, C. (1995). Discourse and Learning in the Classroom: A Sociocultural Approach. In Steffe, L.P. and Gale, J. (Eds.). Constructivism in Education. New Jersey, USA: Lawrence Erlbaum Associates, Inc. 159 - 174.

Wertsch, J.V.; Del Rio, P.D.; and Alvarez, A. (1995). Sociocultural studies: history, action, and mediation. In Wertsch, J.V.; Del Rio, P.D.; and Alvarez, A. (Eds.). Sociocultural Studies of Mind. New York, USA: Cambridge University Press. 1 - 36.

Yuenyong, C. and Narjaikaew, P. (2009). Scientific Literacy and Thailand Science Education. International Journal of Environmental and Science Education, 4(3): 335 - 349. 